\title{
Impact of Sustainability on Tourism Development in Nigeria: A Case Study of Cross River State, Nigeria
}

\author{
${ }^{1}$ Dr. Emeka E. Okonkwo, ${ }^{2}$ Agnes Osarrh Odey \\ ${ }^{1}$ Department of Archaeology and Tourism, University of Nigeria, Nsukka \\ ${ }^{2}$ Department of Hospitality and Tourism Management, Cross River University of Technology, \\ Calabar
}

\begin{abstract}
Cross River State has been a major tourism hub in Nigeria, with an estimated 4500 tourists trooping in each year (Cross River State Tourism Bureau). Tourism is a major part of the state's economy and Cross River prides itself as the nation's paradise; therefore, staging different tourism activities to attract tourists to the state. These activities include the Calabar Christmas Carnival, Obudu Mountain Race and the Leboku Festival. The primary effort of this research therefore is to examine the reasons why tourist choose Cross River State over other tourism destinations in Nigeria, and to critically analyze the social, economic, environmental and cultural impacts of sustainable tourism in the state on the economy, and the local population. To achieve these feat, primary sources of data was used in the likes of questionnaires and semi-structured interviews. Secondary data was also used through books, online sources of scholarly journals, articles, magazines and newspapers. A case study was done on the three geo-political zones of the state - Southern, Central and Northern senatorial districts. A sample size of 190 respondents from the three zones was selected as adequate for this research. Key findings of this study were: (a) Tourists love Cross River because of its serene natural environment and availability of natural parks such as the Cross River National Park. $(b)$ The hosting of major tourism driven festivals such the Calabar Christmas Carnival which is the biggest street party in Africa, the Obudu Mountain Race which attract athletes from all over the world, and the Leboku Festival hosted in the biggest village in West Africa - Ugep. (c) Tourism has contributed immensely to the economy of the state, the sustainability of the environment, and the socio-cultural standing of the locals. It has greatly improved the standard of living and quality of life.
\end{abstract}

Keywords: Sustainable Tourism, Calabar Christmas Carnival, Leboku Festival, Tourism Impacts.

\section{INTRODUCTION}

There is no doubt that tourism is becoming one of the key points focused on by developing countries in an attempt to revitalize their economy (Backhaus, 2008). The labour effectiveness of tourism is a factor that drives the global economy to venture into it because it affords great opportunities for employment (Mathieson, 1982). In Nigeria where there is enormous labour force to drive such a resourceful sector especially in tourism, it can significantly promote both economic and social growth, (Awodele \& Ayeni, 2011). As a result of this, Nigeria as a country has taken bold strides towards the total harnessing of the powerful potentials of tourism. Because of its pertinence, Nigeria has overwhelmingly given thought to this sector of its economy by making heavy investments; thus, diversifying its age long over-dependence on oil (Awodele \& Ayeni, 2011). Be it as it may, with the experiences from other countries such as Egypt and Kenya, there is great need for proper planning and development for the manifestation of the full benefits of sustainable tourism (Figueira, 2001). But when ecotourism is poorly planned and hastily implemented, it can become an absolute disaster to the environmental, social, and economic wellbeing of the tourism destination (Hill \& Tim, 2009).

A decade ago, Cross Rivers State being in the Niger Delta region was $98 \%$ dependent on its rich oil deposits in its southern border with Cameroon (Bakassi Pennesula). But with the ceding of the oil rich region to Nigeria's neighbours, and the seizing of about 96 oil wells by the neighbouring state (Akwa Ibom), Cross River has been forced to depend solely on its huge tourism potential. Different regions are blessed with different natural resources that tend to promote their chances of being tourists' locations. It is important to note that not only landscapes and other natural features can stir tourists' attraction, but also festivals, culture and traditions that have lasted centuries without tampering. Cross River State is blessed with both culture and natural landscape to boost tourism activities (Ottong \& 
Bassey, 2009). Cross River is one of the only states in Nigeria with a very rich natural rainforest that is a host to a variety of animals and plants. A carved-out section of this rainforest in the south is a reserved national park, where wildlife conservation is the essential, this aspect support the main event of the Calabar Christmas Carnival. The central part of Cross River boosts tourism with the annual celebration of the Leboku festival which attracts tourists to the state. The northern part of the state is blessed with a rare mix of temperate and tropical climate at the plateau of the famous Obudu Ranch Resort which is a host to many foreigners because of the favourable weather. The resort also play host to the Obudu Mountain Race - an international event with athletes from all over the world. The Obudu Mountain Race was introduced as a good and vibrant attraction under the leadership of Mr. Donald Duke. This was done as a tool to draw attention and investors to Obudu mountain resort.

All these attractions sway tourists towards Cross River State as compared other locations in Nigeria. The serene and peaceful environment is a major bonus as tourists feel comfortable and safe in the state. These as a result have numerous impacts on the economy of the state, the social and economic standard of the locals and their cultural heritage. These impacts will be analyzed and discussed in detail in the course of this research.

The choice of this topic has been necessitated by the fact that tourism is speedily growing in Cross River State and there is a tendency that without proper planning, the negative impacts will outweigh the positive, therefore it was pertinent to examine these impacts as it will help to furnish officials with the right information on how to handle and plan for these impacts. It is essential that sustainability indicators provide a guide for managers to avoid unforeseen tragedies and disasters, this research therefore is viewed to provide the needed help to the tourism industry to better plan for the future. This study is believed to be able to help the tourism industry in the state to educate the local population on their role of participating actively in the tourism process, as their participation is very essential.

\section{RESEARCH QUESTIONS}

In the quest to understand the situation under study, the following questions come to mind:

1. What are the major obstacles mitigating against tourism sustainability in Cross River State?

2. What are the factors that sway tourists towards Cross River State and how can they be enhanced?

3. In the process of enhancement, what are the impacts of such actions on the local population?

4. What ways can these impacts be sustained if there are positive and limited if they are negative?

\section{AIM AND OBJECTIVES OF THE RESEARCH}

The core aim of this research is to critically observe the impacts of tourism sustainability in Cross River State. Specifically, the main objectives of this research are to:

1. Carefully examine the challenges that tourism sustainability is facing in Cross River State.

2. Analyze the linkages between the impacts of sustainable tourism and the economic, cultural and environmental sustainability of Cross River State.

3. Critically examine the effects of sustainable tourism on the lives of the people of Cross River State.

\section{RESEARCH METHODOLOGY}

The strategy in which the research was conducted was taken into serious consideration. Data collection was done qualitatively and analyzed and represented quantitatively, thereby removing involvement of both deductive and inductive reasoning. In other to examine the impacts of sustainable tourism in Cross River State carefully, a study of the three geo-political zones (North, Central and South) was carefully undertaken.

Data was obtained from both primary and secondary sources. While primary data was gotten from administration of questionnaires and semi-structured interviews, secondary data was obtained from academic journals and articles, books, magazines and internet sources. Because of the nature of the study, the researcher opted to collect qualitative data from the field and carry out a case study, this data however was represented in a quantitative manner (numerically). Out of the 190 respondents chosen from the three geo-political zones, 70 respondents are from the south, 60 each from the north 
and central geo-political zones. This decision of a higher number of respondents in the south was borne out of the higher population and higher level of development given it is the state capital. The data was analyzed in a simple and straightforward manner as it was descriptive in nature.

Specifically, the researcher traveled to Cross River State Nigeria, collected data primarily through the administration of questionnaires and semi-structured interviews which was carried out from September $10^{\text {th }}$ to October $2^{\text {nd }} 2015$. Questionnaires were handed to respondents in the three senatorial zones of the state; the south (Calabar, Akamkpa,), the central (Yakurr, Ikom) and the north (Ogoja, Obudu Obanliku). These questionnaires compromised of both opened and closed ended questions. The three senatorial zones were chosen for the administration of the questionnaire because they represent the three hubs of tourism in the state. The South play host to the Calabar Christmas Carnival, the Tinapa Business Resort, Marina Resort, Old Residency Museum and the Cross River National Park, while the Central host the annual Leboku Festival and the North is the location of the Obudu Mountain Resort and host of the Obudu Mountain Race. A total of 190 questionnaires were handed out to respondents in these three areas and 158 were collected, recording a response rate of $83.2 \%$.

Also, a semi-structured interview method was used to obtain primary data. This format was used with staff of the Cross River State Tourism Board and was granted the permission to engage the staff in such a capacity. In separate meetings a total of 10 staff were issued the semi-structured interview, while the first meeting was 6 staffs, the second was with 4 staffs. The data gotten was analyzed together with the questionnaire.

\section{SAMPling AND SAMPLing TEChNiQUeS}

This research study took into consideration the population size, mean deviation, margin of error and population standard deviation during sampling.

Sample Size $=190$

The formula

Where $\mathrm{E}=$ Margin of Error

$\mathrm{Z} / 2=$ Confidence probability boundary

Б = Estimate population standard deviation.

Therefore this gave the researcher the chose sample size of 190 respondents. From the 190, 70 was for the state capital were 10 were chosen for the semi-structured interview, and 60 each of the central and northern senatorial districts.

It was pertinent that the research use is a mixed sampling technique. Therefore, this survey used the simple random technique and the purposive sampling technique also known as judgmental, selective, or subjective sampling. Considering that each element in the survey population needs to have an equal chance of selection, the simple random sampling method was adopted (Maha , 2002). This method was used for the semi-structured interview with the staff of Cross River State Tourism Board (CRSTB).

\section{Literature REVIEW}

According to Foot (1990) and Bowler, English, \& Cordell (1999) increases in the demand for recreational areas and facilities have been enhanced by the fast growth of world population. Therefore over recent years, the travel industry and ecotourism have been on the rise (Bowler, English, \& Cordell, 1999) and the movement of tourists' into ecotourism areas improves the living standard of the host community. Tourism remains the fastest growing industry in the world and up until now is the main mainstay economy for most countries in the world (Nuva \& Shamsudin, 2009). In Africa, Kenya, Madagascar, Egypt and Nigeria's gross domestic products are constantly boosted by tourism (Isaac, 2000). As noted by Abbot, Thomas, Gardner, Neba, \& Khen (2001) incorporating our environment and ecotourism have come to be a distinct way of involving the indigenous community to throw in their weight and support the retention and care for natural resources and locations that boost tourism. Tourism therefore is identified to be a force that is effective enough to add steam to an economy and is globally recognized as the fastest growing industry (Raymond, 2001). The growth in the tourism industry has not come in total isolation but many factors such as technology and global 
economic development has played a major role in the rapid growth of the tourism industry (Isaac, 2000).

As a result of this fast growth, tourism has added more value to the overall disposable revenue, leisure demand, and competition in the tourism industry (Raymond, 2001). Besculides, Lee, \& McCormick, (2002) and Oh (2005) opined that tourism has significant advantages in the form of job creation, income and revenue generation and great improvement to the standard of living to tourism organizations, government and private individuals. Hence, it is now a known fact that tourism can bring about development in a nation especially as one of the fastest growing industries; but the challenge is how to make it sustainable to avoid a negative footprint (Zhenhna, 2003).

\section{TOURISM SUSTAINABILITY}

The term sustainability is so wide that reaching a definite definition can be very difficult (Cooper, Fletcher, Flyall, Gilberth, \& Wanhill, 2005). Since 1987 that the world commission on environment released a report tagged 'sustainable development' the concept has been successful and has since gained global recognition (Ayeni \& Ebohon , 2012). The World Tourism Organization defines sustainable tourism to mean tourism that takes its present and future social, economic and environmental impacts, taking into cognizance the tourists' needs, the needs of the industry, the government and entire communities concerned. The World Commission on Environment and Development (WCED) defined sustainable development as a growth that satisfies the current generation without depriving the capability of the future generations to meet their own demands (WCED, 1987).

A sustainable tourism development practice does not compromise the future needs for present satisfaction. Both the tourist and host community are considered in a way that is beneficial and brings about development. Such a process protects, contributes and sustains the culture and environment at large while creating future opportunities. Tourism includes a good/considerable number of people including local population, stakeholders and tourists; UNWTO considers participation a key process for achieving sustainable development.

Therefore according to WTO (2014) for tourism to be termed sustainable it should be able to:

i. Use optimally the resources from the environment which are natural and that establish a vital part in the advancement and growth of tourism while conserving important environmental processes and aiding culture.

ii. Respect the social and cultural sincerity of the people, protect their environment, their living and traditional heritage and values, in addition, and enhance either inter-cultural knowledge and acceptance, and

iii. Make certain achievable, economic operations in the long-term, make available socio-economic remunerations to stakeholders and are evenly spread, which includes stable employment and job opportunities and social services to host communities, and supporting poverty alleviation.

Sustainable tourism development involves the active contribution of all required shareholders also trusted political body which will determine a broad sense of participation and building of a greater consensus. Sustainability is tourism ensures also a competent and better quality of customer satisfaction (Chockalingam \& Ganesh, 2010), educating and informing them about sustainability benefits and encouraging viable tourism practices (Perujodi, 2011). While tourism sustainability is known to be a great factor in the enhancement of socio-economic development in many countries because it bodes well with other sectors of the economy. Raymond (2001) states that for the tourism benefits to accrue a particular nation, it is dependents on the local conditions of that nation and Manwa (2012) argue that direct tourism benefit from the community makes tourism sustainable, as they will feel a need to protect the resources. Hall (2007) shares the sentiment that though, they are different type of tourism, but the extent of economic benefit in a nation rest on the tourist expectations and ability of host community to provide adequate facilities.

Tourism activities no matter the rationale behind it, be it holidays, business, travel, adventure, and ecotourism need to be sustainable (Godfrey \& Clarke, 2000). Sustainable tourism aims to achieve economic sustainability, community success, reduced unemployment rate, good social wellbeing, tourist fulfillment, rich culture, physical integrity, natural diversity, efficient resources and a pure environment (Ofem, 2012). In other to accomplish these, one must meet some criteria. These criteria 
help in the identification of very important issues which aid managers in the tourism industry to quickly and effectively answer the call and sustain what makes a destination capture the attention of the tourists. The key issues are referred to as indicators.

\section{Sustainability Indicators}

Indicators are a yardstick used to measure level of seriousness of current issues, signs, of situations that might cause problems or are unfavourable, a yardstick to measure the risk and the rationale for taking an action, and a way to discover and enumerate the outcome of such activities that are taken. From time to time, indicators are sets of information used to gauge the changes that are pertinent to tourism management and also its development (Aniah, Eja, \& Otu, 2009). If these indicators are used properly, there can be very important tools in management. Very good indicators can provide useful information to guide against pressing problems that might surface unexpectedly (Zhenhna, 2003).

For more than ten years there have been tremendous efforts in the field of sustainable tourism indicators directed towards research and capacity building activities. A bulk of this research work is done by the United Nations World Tourism Organization (UNWTO). The purpose of establishing these sustainability indicators is to make a provision for people in tourism management for critical information to be available to them so that they can look forward to and stop unsustainable and unacceptable outcomes (Lindberg \& Hawkins, 1993). Risks facing key assets are better define through a grasp of better information presented by indicators.

Below are some of the importance of good definition and the use of indicators in sustainable tourism which comprise:

- the ability to constantly keep an eye on improvements and building those situations into management

- there is a greater percentage of good decision making and lower risks involved

- ability to identify upcoming issues and taking proactive preventive measures

- impacts identification and the allowance of corrective actions were necessary

- when plans are implemented, it enables the measure of the performance and evaluation of progress

There is the requirement of an extra-ordinarily sound planning process in other to achieve sustainable development and also a constant supervision of the fundamental activities that support tourism and its purpose. These might include assets maintenance, engagement of the locals, and tourism contribution in the initial and subsequent development process of the destination. Indicators are basic components of the development process (Nuva \& Shamsudin, 2009). Without these indicators there is the absence of a checklist and a yardstick to measure the sustainability of a tourist location and might lead to various challenges and impacts on the environment, economy and even the population.

\section{IMPACTS OF SUSTAINABLE TOURISM DEVELOPMENT}

Though sustainability is a serious issue in the tourism industry with great concern on the part of stakeholders who want to make money and at the same time makes it over a long period of time. In other to achieve this feat, most developers could engage in quick fix, thereby resulting in the damage of the tourism destination and the natural environment (Aniah, Eja, \& Otu, 2009). The impacts of sustainable tourism could be positive as well as negative. Many scholars have argued about which of these impacts have an edge above the other. In his argument, Kigoth (2000), assessed that the impacts of sustainability could be adverse or beneficial depending on some certain scale of measurement or a function of certain form of activities undertaken by the tourists, the environment and socio-economic characteristic of the area and the degree to which the industry is planned and managed.

The effects of sustainable tourism in the long run could be disastrous, dangerous and unquantifiable. In economy that relates to ecology, the rule of inter-dependency is in full view. Therefore the rule of isolation in action is impossible, and this policy must be carefully and thoroughly thought through as if disregarded this can create adverse and terrible effects for both the economy and the ecology (Besculides, Lee, \& McCormick, 2002). So many scholars have in one point or other questioned the basis of the concept of sustainability. Though this argument has been around for decades, there are also a lot of scholars who fully support and believe in the concept of sustainable tourism and development. As expected these scholars are much more in number than the opposition (Hall, 2007). 
Mihalia (2000) has the view that for tourism to be sustainable it needs continuity. It should create employment, improve the living standard of the host community, increase the infrastructural development, and social amenities while placing the host community on the world map with the increased influx of tourists visiting the area. Mihalia (2000) further argued that by the constant improvement on the level of infrastructure, sustainable tourism could form a basis and stepping stone to the industrial development of the region in question.

The UNTW in 2004 held the view that either direct or indirect employment is massively created by tourism. Accordingly about 140million jobs are created in the Asian and Pacific region, this account for about $8.9 \%$ of the total population. Also taken in account is the fact that employment in the tourism sector of the North-East Asia, has come close to creating about 86million jobs, or say $10.1 \%$ of the overall employment. In China about 1 in every 10 persons have jobs in an industry that is tourism related. A support of UNTWO's came from Zhenhna (2003), who following a research, wrote that in Oceania the tourism sector accounts for about $14.5 \%$ of the total employment that is approximately 1 in every 6.9 jobs in the area. The issue of employment has been a reason why tourism sustainability has been given a good review by major scholars in the industry.

\section{Data Presentation and Analysis: Impacts of Sustainable Tourism DeVelopment in Cross River State}

After giving out 190 questionnaires and a response rate of $83.3 \%$ was recorded amounting to 158 respondents returning their questionnaires, this survey was conducted in the south, central and northern Cross River State in Nigeria. The Statistical Package for Social Sciences Software (SPSSS) was used to analyze the collected, while the information gotten from the semi-structured interview which was carried out among 17 staffs of the Cross River Tourism Bureau was analyzed differently and descriptively. This part of discus therefore fulfills the objectives of this research by presenting and analyzing the data gotten from the field in various categories.

\subsection{Holiday Patterns of Respondents}

In the course of this research, the researchers studied the holiday pattern and behaviours of the respondents. Most respondents travel mostly by car while some others spend most of their money on shopping and majority of the respondents stay in hotels when they go for tourism activities. This category of data was analyzed in this section as follows:

\section{i. Trips to Tourism Activities in Cross River State}

With most of the respondents actually residing in Cross River State while going to such tourism activities or have attended tourism activities at one point or the other. Just $14(8.86 \%)$ out of the 158 respondents have never attended any event even when they knew of it. 17 (10.76\%), 30 (18.98\%) and $24(15.19 \%)$ had attended an event once, twice and thrice respectively. But the tourism viability in the state was evident when 73 (46.21\%) of respondents have attended events more than four times (see table 1).

Table1. Number of Times Participated in Tourism Events

\begin{tabular}{|l|l|l|l|l|l|}
\hline & None & One time & Two times & Three times & Four and More \\
\hline Below 18 & 8 & 2 & 0 & 0 & 0 \\
\hline $19-39$ years & 2 & 7 & 20 & 5 & 10 \\
\hline $40-59$ years & 2 & 6 & 10 & 15 & 28 \\
\hline $60-79$ years & 1 & 2 & 0 & 3 & 33 \\
\hline 80 -above & 1 & 0 & 0 & 1 & 2 \\
\hline
\end{tabular}

A cross arrangement between age range and number of time participated in an event

\section{ii.Mode of Transportation to Tourist Activity}

Because transportation is a core issue in tourism development, this study took into consideration the mode of transportation that the respondents have taken part in a tourism event used. When respondents were questioned on the mode of transportation used, $61.39 \%$ of the respondents admit to using cars, while $11.39 \%, 3.79 \%, 1.27 \%$ and $22.16 \%$ admitted to using airplanes, boats, bicycles and foot respectively. Though, no respondent admitted to using a ferry. 


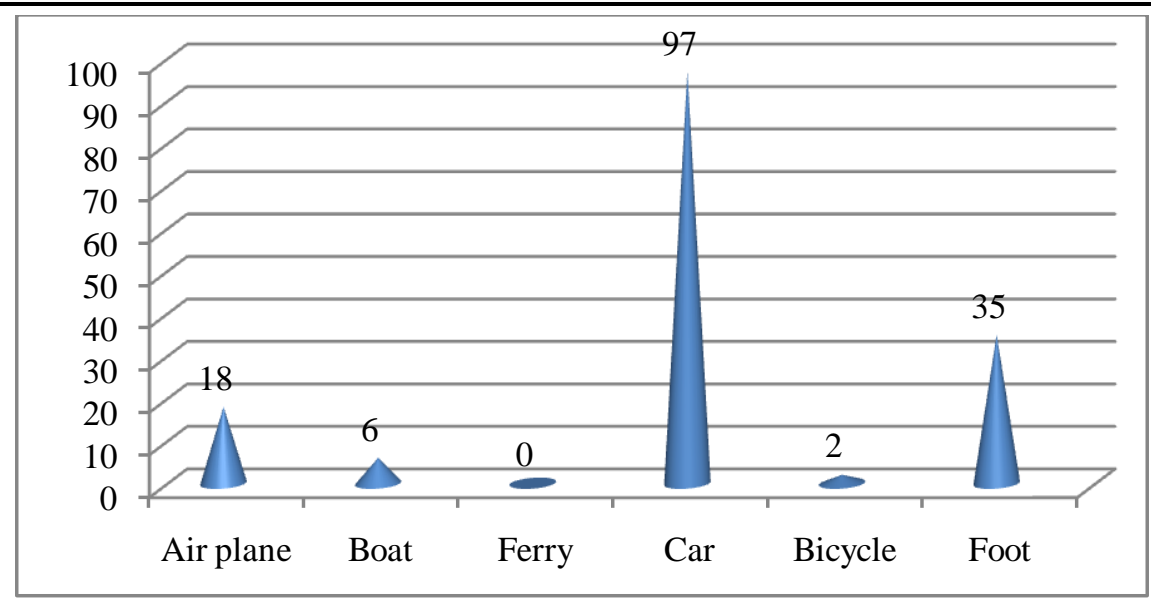

Figure1. Mode of Transportation to Tourist Activity

\section{iii. Preferred Place of Residence While Touring}

When respondents were quizzed on where they preferred to stay when attending tourism activities, most of the respondents stay in hotels (73 out of 158), followed by 38 respondents who preferred staying in a resort, 10 of the respondents liked staying in hostels, 22 in campsite/tour park and 15 in a friend's or family's house. However no respondent admitted liking to stay in a self-catering apartment.

\section{iv. Did You Consume Any Local Food?}

Culture is multifaceted and food is one of it. When data from the field was analyzed with the SPSS software, the section were respondents were quizzed about eating local food was analyzed thus; 108 respondents $(68.35 \%)$ agreed that they do, just 10 respondents $(6.32 \%)$ said they don't while 40 respondents $(25.32 \%)$ said food consumption was not applicable to their activities.

\section{v. How Long Did You Stay?}

Length of stay is very important in tourism, therefore it was considered during field work. After data collection and analysis by the Statistical Package for the Social Sciences (SPSS), it was found out that a great $55.70 \%$ of respondents stayed through the duration of an event, $17.72 \%$ stayed for four (4) days, $11.39 \%$ stayed for three (3) days while $12.66 \%$ and $2.53 \%$ stayed for two and one day respectively.

Table2. Sex of Respondents and Days Spent at Tourism Destinations

\begin{tabular}{|l|l|l|l|l|l|}
\hline & One day & Two days & Three days & Four days & Duration of event \\
\hline Male & 15 & 1 & 14 & 10 & 53 \\
\hline Female & 5 & 3 & 4 & 18 & 35 \\
\hline
\end{tabular}

\section{vi. Spending Power of Respondents}

When asked about their spending power, majority of the respondents agreed to spend $\$ 2000$ - $\$ 5000$ naira per day amounting to $32.28 \%, 25.32 \%$ followed up with a spending power of $\$ 21,100$ $\$ 30,000$ naira while $14.56 \%$ spend $\$ 31,100$ naira and beyond and $11.39 \%$ spend about $\$ 6,100$ $\$ 10,000$ with just $8.86 \%$ of respondents spending amounts varying from these ones.

\section{vii. The Bulk of Expenditure Covers?}

Certain things are given priority while on tour, so when quizzed about what takes the bulk of their money and after analysis with the SPSS used by the researchers for this research, $27.23 \%$ of respondents spend more on drinks, 35\% spend most of their money on shopping, $13.29 \%$ was analyzed to spend a chunk of their cash on intra-city transportation, $14.56 \%$ spend more on food, while $9.49 \%$ spent their cash on other things like paid recreation as represented in table 3 below.

Table3. Representation of Bulk of Expenditure Covers

\begin{tabular}{|l|l|l|}
\hline Item & Frequency & Percentage (\%) \\
\hline Drinks & 43 & 27.23 \\
\hline Food & 23 & 14.56 \\
\hline
\end{tabular}


Dr. Emeka E. Okonkwo \& Agnes Osarrh Odey

\begin{tabular}{|l|l|l|}
\hline \hline Shopping & 56 & 35.44 \\
\hline Intra-city transport & 21 & 13.29 \\
\hline Others (recreational activities) & 15 & 9.49 \\
\hline
\end{tabular}

\subsection{Factors Considered by Respondents When Traveling to a Destination}

\section{i. Proximity}

It is interesting to find out that after the data was analyzed, majority of respondents $(32.28 \%)$ felt proximity to a tourists' destination is very important, $15.19 \%$ said it is important, $14.56 \%$, of respondents don't really care and $24.68 \%$ thought it is not important while $13.29 \%$ thought it is not very important.

\section{ii.Cross River State Weather}

Interestingly Cross River State has a very friendly weather, and respondents showed the importance of these aspects when $49.37 \%$ says is very important, $18.99 \%$ say it is important in choosing CRS, $15.19 \%$ don't consider the weather, $8.86 \%$ say it is not important while just $7.59 \%$ say it is not very important (see table 4).

Table4. A Cross Tabulation of Nationality and Weather Condition Response

\begin{tabular}{|l|l|l|l|l|l|}
\hline & Very important & Important & I don't consider & Not important & Not very important \\
\hline Cameroonians & 4 & 0 & 0 & 0 & 0 \\
\hline Nigerians & 69 & 30 & 24 & 14 & 12 \\
\hline Kenyans & 3 & & 0 & 0 & 0 \\
\hline Indians & 2 & 0 & 0 & 0 & 0 \\
\hline
\end{tabular}

\section{iii. Political Stability and Security}

Peace and security is paramount to a destination. Respondents were asked if they consider the political stability of a destination before traveling and their response was analyzed thus: 98 respondents said it is very important, 30 said it is important, 12 said they don't consider the issue, while 10 and 8 respondents see it as not important and a not very important issue.

Table5. A Cross Tabulation of Age Range of Respondent on Political Stability and Security

\begin{tabular}{|l|l|l|l|l|l|}
\hline & Very important & Important & I don't consider & Not important & Not very important \\
\hline Below $18 \mathrm{yrs}$ & 2 & 8 & 0 & 0 & 0 \\
\hline $18-39$ & 20 & 10 & 6 & 2 & 6 \\
\hline $40-59$ & 60 & 0 & 0 & 0 & 1 \\
\hline $60-79$ & 12 & 12 & 6 & 8 & 1 \\
\hline 80 and above & 4 & 0 & 0 & 0 & 0 \\
\hline
\end{tabular}

\section{iv. Tourism Resources and Facilities}

Before there can be tourism, there must be resources that attract tourists to a destination. Respondents were asked about how availability of tourism resources affect their choices of a destination, as represented in figure 2. 102 respondents agreed that it was very important, 48 consider it important, 6 say they don't consider, 2 respondents say it is not important, while no respondent considered it as not being very important.

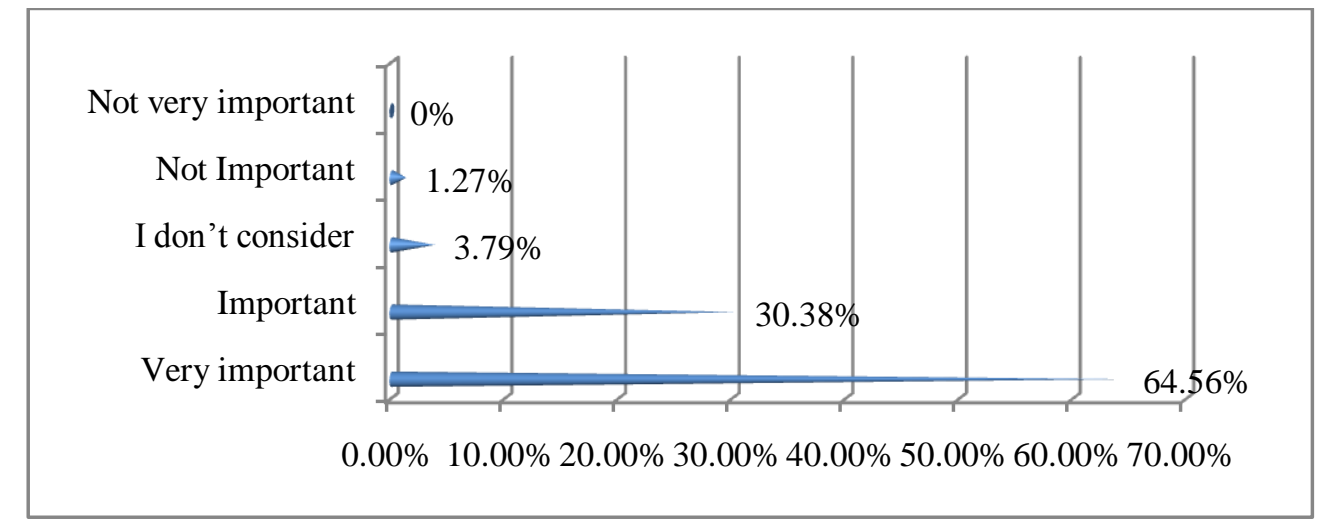

Figure2. Tourism Resources and Facilities 


\section{v. Accommodation Conditions}

As tourists need to pass the night in Cross River State, respondents were quizzed if they consider the quality of accommodation before traveling. After the data was analyzed, 98 out of 158 respondents agreed that it is very important for a destination, 46 deem it important, and 9 don't really consider it before traveling while 4 respondents apiece see it as not important and not very important (see table 5).

Table5. Accommodation Conditions

\begin{tabular}{|l|l|l|}
\hline Variable & Frequency & Percentage (\%) \\
\hline Very important & 98 & 62.03 \\
\hline Important & 46 & 29.11 \\
\hline I don't consider & 9 & 5.70 \\
\hline Not important & 4 & 2.53 \\
\hline Not very important & 4 & 2.53 \\
\hline
\end{tabular}

\section{vi. The Chance to Take a Certain Adventure}

Respondents were asked if they consider the chance to take a certain adventure during their trip. Overwhelmingly, 92 respondents said it is very important, 44 see it as being important, 11 don't consider it, while 8 and 3 see it as being not important and also being not very important respectively.

\subsection{Importance of Tourists' Activities}

\section{i. Improves Standard of Living}

There is no doubt that tourism has significant effects on the economy, environment, and socio-cultural aspects of Cross River State. Therefore, the researchers quizzed respondents on the impacts of tourism activities on the standard of living, the data collected was then analyzed as a result, 44 respondents strongly agree that it improves the standard of living, 38 agrees with it, 50 are not sure it does, 20 disagree while 6 strongly disagree with this.

\section{ii.Improves Infrastructural Development}

Respondents were asked if tourism improves the development of infrastructure, an overwhelming $50.65 \%$ agreed strongly, however, $24.05 \%$ of respondents are no sure it is responsible for that. $11.39 \%$ actually just agreed, while $5.06 \%$ and $8.86 \%$ disagreed and strongly disagreed as well. This is represented in table 6 .

Table6. Improves Infrastructural Development Responses

\begin{tabular}{|l|l|l|}
\hline Variable & Frequency & Percentage (\%) \\
\hline Strongly agree & 80 & 50.65 \\
\hline Agree & 18 & 11.39 \\
\hline Not sure & 38 & 24.05 \\
\hline Disagree & 8 & 5.06 \\
\hline Strongly disagree & 14 & 8.86 \\
\hline
\end{tabular}

Table6. Frequency Distribution of Nationality of Respondents

\begin{tabular}{|l|l|l|l|l|l|}
\hline Nationality & Strongly agree & Agree & Not sure & Disagree & Strongly disagree \\
\hline Cameroonians & 3 & 1 & 0 & 0 & 0 \\
\hline Nigerians & 73 & 16 & 38 & 8 & 14 \\
\hline Indians & 2 & 0 & 0 & 0 & 0 \\
\hline Kenyans & 2 & 1 & 0 & 0 & 0 \\
\hline
\end{tabular}

\section{iii. Help Sustain The Environment}

Quizzed on tourism's effect on environmental sustainability, respondents asserted that tourism help sustain the environment with 68 respondents strongly agreed to that, 42 agreed to tourism's ability to sustain the environment, 3 however were not sure, 30 respondents disagreed with this assertion while 13 strongly disagreed. This data is represented in table 8 .

Table8. Help Sustain the Environment Responses

\begin{tabular}{|l|l|l|l|l|l|}
\hline & Strongly agree & Agree & Not sure & Disagree & Strongly disagree \\
\hline Below 18yrs & 5 & 3 & 2 & 0 & 0 \\
\hline $18-39 y \mathrm{ys}$ & 20 & 10 & 0 & 8 & 6 \\
\hline $40-59 \mathrm{yrs}$ & 40 & 20 & 0 & 0 & 1 \\
\hline $60-79 \mathrm{yrs}$ & 2 & 6 & 1 & 22 & 6 \\
\hline $80 \mathrm{yrss}-$ above & 1 & 3 & 0 & 0 & 0 \\
\hline
\end{tabular}




\section{iv. Open Doors for New Business}

Many of the respondents believe that tourism brings about the development of new businesses, this is shown in the field survey where 72 respondents say they strongly agree that tourism open doors to new businesses, 48 other respondents agreed also to this fact, 18 were however not sure, 20 disagreed while 10 strongly disagreed with this. The data as analyzed by the Package for the Social Sciences software is represented in table 9.

Table9. Frequency Distribution of Open Door for New Business Responses

\begin{tabular}{|l|l|l|l|l|l|}
\hline & Strongly agreed & Agreed & Not sure & Disagreed & Strongly disagreed \\
\hline Frequency & 72 & 48 & 18 & 20 & 10 \\
\hline Percentage & $45.57 \%$ & $24.05 \%$ & $11.39 \%$ & $12.66 \%$ & $6.33 \%$ \\
\hline
\end{tabular}

\section{v. Crime Rate is Increased During Peak Periods}

98 respondents strongly agreed that crime rate is significantly increased during peak of tourism activities, 16 agreed, 24 where actually not sure, 30 disagreed while 12 respondents strongly disagreed.

\section{vi. Causes Environmental Pollution}

When respondents were asked if tourism activities contribute to environmental pollution, 58 respondents strongly agreed that tourism activities cause pollution, 30 agreed, 17 were not sure, 5 disagreed while 48 strongly disagreed.

\section{vii. Prostitution is Checked}

Respondents were asked if tourism help to check prostitution in Cross River State. 56 respondents were found to strongly disagree with this, 48 disagreed, the number of respondents who were not sure and those that strongly agreed were at a tie (22), while the number of respondents who just agreed were 10 .

\section{viii.Biodiversity is Conserved}

Respondents shared their various views when quizzed if tourism conserved biodiversity, in their response after the analysis by Statistical Package for the Social Sciences software, there was a tie between those that strongly agree and those that strongly disagree $(31.65 \%), 22.15 \%$ of the respondents disagreed, $9.49 \%$ agreed while $5.06 \%$ were not sure if tourism conserve biodiversity or not.

\section{ix. Wildlife is Protected}

When respondents were asked if wildlife conservation is enhanced through tourism, they overwhelmingly agreed with 98 respondents strongly agreeing to this question, 20 respondents just agreed, however, 19 were not sure, 6 disagreed while 15 strongly disagreed.

\section{DisCUSSION OF FINDINGS}

Based on the aim and objectives of this research outlined earlier, the researchers made the following findings:

The researchers found out that contrary to government announcements about funding of the sector, very little of the said amount is actually remitted to the sector. Also from the analysis made of the Tourism Bureau, the researchers found out that the tourism industry suffered from misappropriation and mismanagement of funds also managed by incompetent and fraudulent personnel who lack adequate training to man this sector. Again, there were inadequate logistics, incongruous policies, mundane planning that does not relate with contemporary tourism planning.

Through this study, the researchers realized that the age range of 40-59 years and 60-70 years have made more journeys to attend tourism activities or to tourism locations for holidays or recreation. This brings to light the viability of the sector and level of participation. Tourists also showed that they prefer traveling by car (road) more than other means of transportation. The choice of this mode is made easy because the others are seldom available. But the availability of good access roads to tourist locations is not there. Therefore, it takes 6 hours to make a journey of two and half hours. These have significantly discouraged tourists from visiting the state. 
In terms of accommodation, tourists preferred to stay in hotels and resorts. The primary rationale behind this decision was that tourists preferred good facilities, customer service, luxury, comfort, and naturally serene environment. It was also realized that the local people were not immensely involved in tourism activities as major stakeholders in hotel management and catering, resort management and carnival planning are either Nigerians from other states or foreigners from South Africa or other expatriates. This caused a feeling of neglect towards the locals.

Through this study, it was further observed that tourists believe there is an increment in crime rate during peak periods such as the Carnival Calabar period. Though they expressed feeling comfortable and safe, they however pointed out that the rate of crime is significantly increased. This is as a result of the arrival of foreigners with expensive assets and belongings and on the fact that most of these high crime rate areas are made up low income groups, unemployed and is located at the urban fringes with low security. However the monthly crime rate recorded in the resorts area revealed that $32 \%$ and $10.6 \%$ of crime were committed during November and December. However, this could be based on the fact that these two months constitute the festive periods which is usually accompanied with events.

It was also realized that tourism in Cross River State has significantly contributed to infrastructural development. This is evident in the availability of world class facilities, hotels and resorts such as Tinapa Business Resort and Obudu Ranch Resort, Channel View hotels and other world class facilities which have sprung up through tourism. Because of the use of foreigners in the Calabar Carnival festival and other related tourism activities, it was realized that young girls from age $17-35$ years have been made to go into prostitution at peak periods. This is so because; they are not involved in tourism activities that can provide a means of livelihood for them.

In terms of tourism activities and locations, the researchers found out that the state is blessed with various forms of tourist cynosures, from wildlife species, elevations, favourable environment, green mangrove forest, falls, caves, rare/endangered species such as lowland gorillas, outstanding ethnic dynamics, beautifully made local craft and warm hospitality. Most of these resources are yet unharnessed for tourism purposes. Of a truth, Cross River State government has for a long time realized the positive socio-economic impacts or benefits of tourism that is why the state government has put in so much to diversify the economy of the state through tourism. There is great potential in this sector.

In terms of unemployment, the teeming youths were found to be unemployed and this result in the high rate of social unrest and crime rate. This can be attributed to two major factors: (1) the fact that these youths are unemployable (2) the fact that government have not made provisions for employment especially with its policy of recruiting foreign workers. In terms of environmental pollution or protection, the researcher found out that while in the major city of Calabar, the government have kept the environment clean and green in other tourist locations such as the Cross River National Park and the Obudu Ranch Resort, the introduction of man-made structures have destabilized the ecosystem disrupting the natural existence of biodiversity and wildlife. This is as a result of man's constant intrusion into the natural habitat of animals and as such scaring them, also the constant construction work that destabilize the soil structure. During peak periods, tourism has also caused environmental pollution in tourist location which has been harmful to both plants and animals. The dynamites used in breaking the rocks for easy dualization of the ranch road had its effects in recent times. Today, cases are reported of landslides that have seriously threatened vehicular movement to and from the ranch.

\section{RECOMMENDATIONS}

The following recommendations have been drawn from the findings made earlier in this paper.

\section{Government Funding}

Great financial power will help this sector of the economy. The government of the state should therefore budget more funding towards the development of the tourism industry. Now that the global oil prices are a record low, there is urgent need to diversify the economy and tourism is the fastest ways for the government to generate foreign exchange and internal revenue. Therefore, projects that will boost the sector such as good roads, telecommunication, clean environment, wholesome water, electrification and a very good transportation should be initiated to boost tourism. 


\section{Good Transportation Network}

A good tourism destination must be accessible either by road, water, air or all of the aforementioned where possible. The government on its part must partner with investors to build roads and rail networks to boost tourism. The non-functionality of the Obudu Ranch Resort airstrip has hindered tourists from accessing the area because the other available option is the road which is in a deplorable condition. Government should as a matter of urgency dredge the seaport so that it can support docking, rehabilitate the Ranch airstrip to support local flights to the area while constantly maintaining the roads. This will no doubt increase the number of tourists.

\section{Involvement of the Local Population}

The local people should be greatly involved in tourism in the state. This as earlier stated will provide jobs, reduce crime rate, and make them have a sense of belonging which will allow them to protect the infrastructure in their locations. It will also promote cultural exchange between the tourists and the people and help them feel comfortable enough to interact with the tourists without having a feeling being cheated which might result to different social vices.

\section{Use of Professionals and Sustainability}

It is very important for government to use qualified personnel in the tourism sector because they know how to manage resources in terms of finance and infrastructure. Tourism professionals will ensure the sustainability of tourism sites, leaving them in their natural state or with minimum adjustments so that future generations can also use the same resources.

\section{Continuity and Rebranding}

Governance is a continuous process, so good policies of the past administration should be executed by the next. This level of continuity will afford the policy makers ample time to execute their plans without disruption. Also rebranding the tourism sector is also an important aspect that attracts more tourists.

\section{Marketing and Advertising}

Marketing a destination is very vital, that is why government with its policy of rebranding should endeavor to create avenues that will attract both investors and customers alike. The government should go in partnership with major investors to boost tourism. Destinations should be sold to the public through various media of advertisement.

\section{Good Health and Recreational Facilities}

The government should provide good health facilities at tourism locations, not just to be used by tourists but also made available to the local people. This will again give them a feeling of benefit. Modern recreational facilities should be provided for the comfort of the tourists and parks and other facilities like schools, hospitals, town centers etc. should be provided for the local people too.

\section{Coordination and Supervision of Stakeholders}

Cross River State government through State Tourism Board should inspect all stakeholders who run private hotel and recreational business to make sure they are up to date with the set standards both in facilities and in services. Adequate sanctions should be directed to defaulters as this will keep all stakeholders on their toes and guide them to provide the best services that are required of them.

\section{CONClusion}

Tourism in Cross River could work extremely well if measures are put in place to sanitize and restructure the system. The local population is of great importance to the success of tourism because they fuel the growth of the sector when they perceive they will derive benefit from tourism they tend to cooperate with the stakeholders (Eugene, Leif , \& Carolyn, 2010). Facilities and infrastructure are essential for the growth of the tourism industry. It is likely that more tourists would troop in to use world class facilities if available. The case for good motor-able roads, ports, airstrips and rail network also facilitate the movement of tourists from one location to the other (Pate \& Loomis, 1997).

Security and wellbeing of tourists is also an essential tourism aspect. The safety of the tourist must be considered. Although from antecedent, no tourist has been kidnapped in Cross River State that however cannot be said of picking pockets, stealing and robbery. The local peoples feeling of responsibility is derived from their involvement, something that the government has neglected. 
Construction ethics neglect has led to many forms of environment degradation. Because of bad construction of roads and drainages, there tend to be erosion everywhere, not only wiping away the topsoil that is needed for agriculture, but also creating very expansive gullies cutting across major roads. The need for infrastructural development should be balanced by good workmanship under the supervision of professionals. Other forms of environmental pollution like proper refuse disposal are also a challenge and the need to make this a priority is of great importance to tourism in the state (Coldecott, Oates, \& Ruitenbeek, 1990).

Discontinuity in government policies have hindered the progress of tourism in the state as each incoming government tend to roll out different policies that will not at the end be in tune with the original plan of the previous administration. This has led to a stop-and-start system and grossly affected the growth of the sector as major tourist locations now look a shadow of their former glorious self. In the future, further research can be carried out on the following areas: 1) Biodiversity conservation and its relationship with tourism in Cross River State. 2) Tourism and Infrastructure: Impacts on the environment. 3) The involvement and participation of the local people in tourism; effects and impacts. 4) Rebranding ecotourism in Cross River State, and 5) The effect of government policies on tourism in Cross River State.

\section{Pictures of the Tourism Attractions in Cross River State}

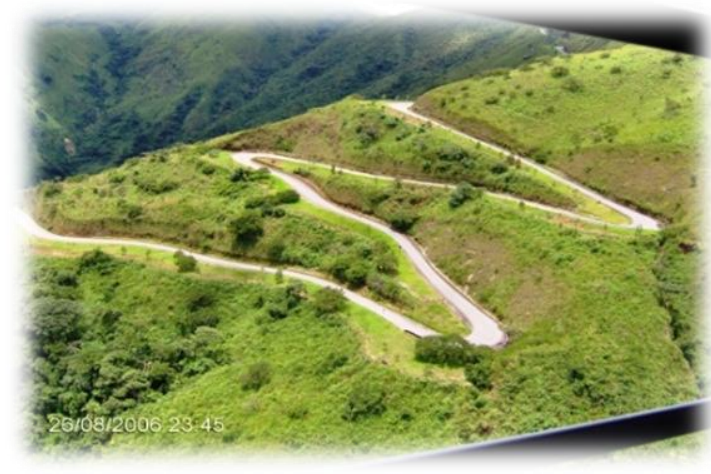

Obudu Ranch Resort road

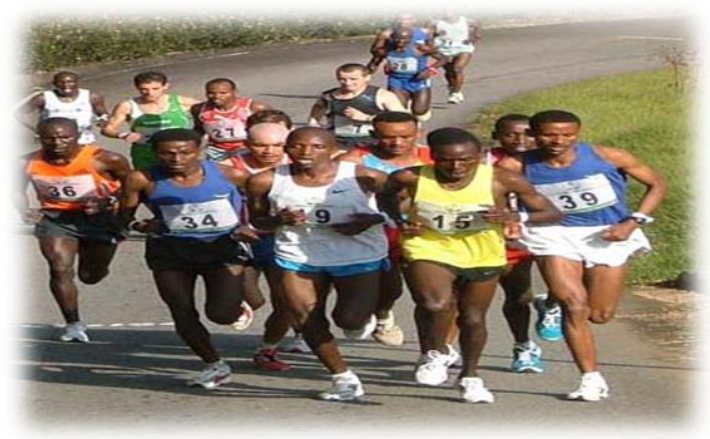

Obudu Mountain Race

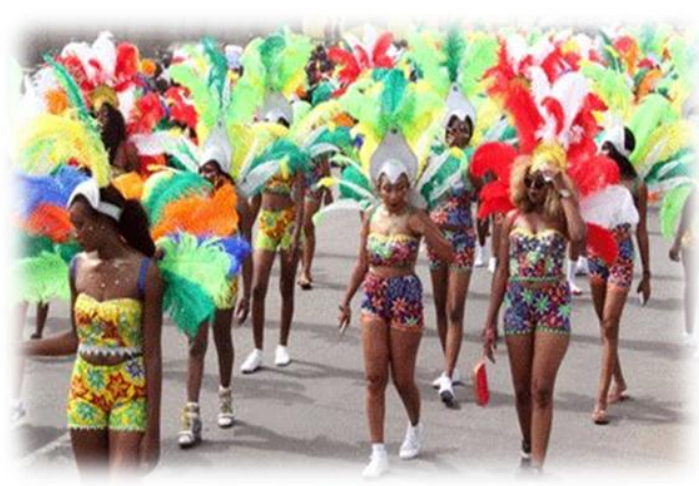

Calabar Adult Carnival

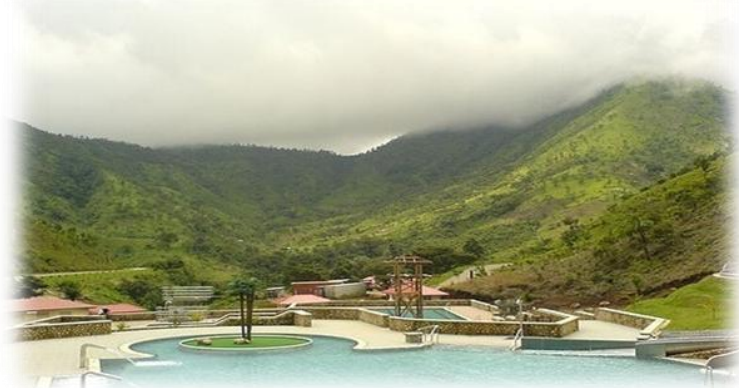

Obudu Ranch Resort Water Park

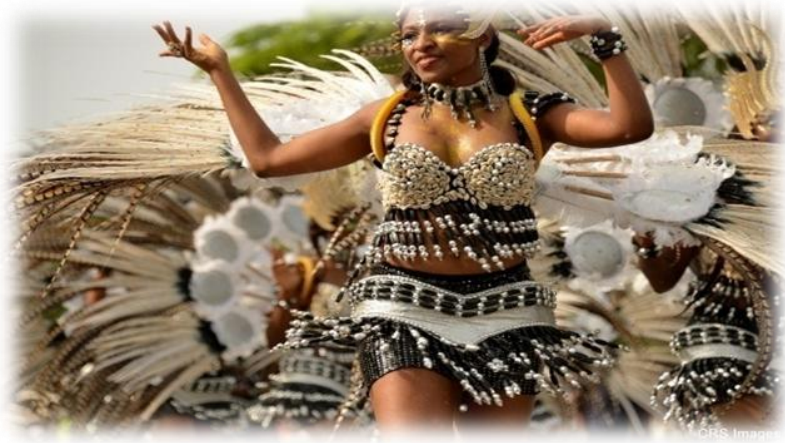

The Adult Calabar Chrismas Carnival

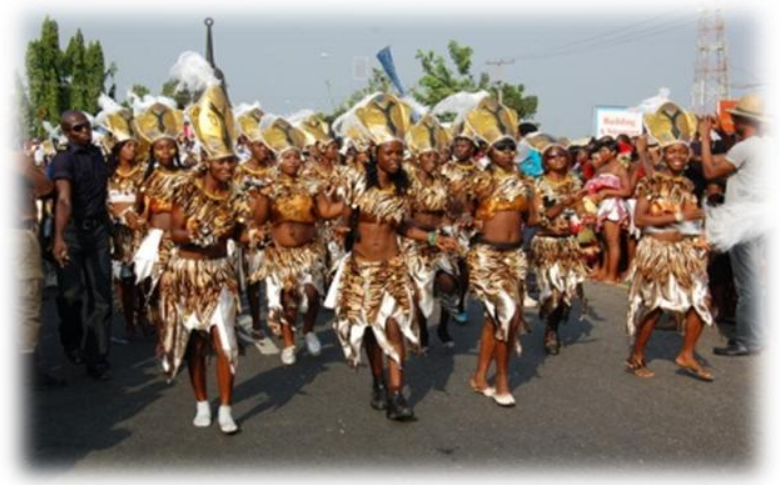

Calabar Adult Carnival 


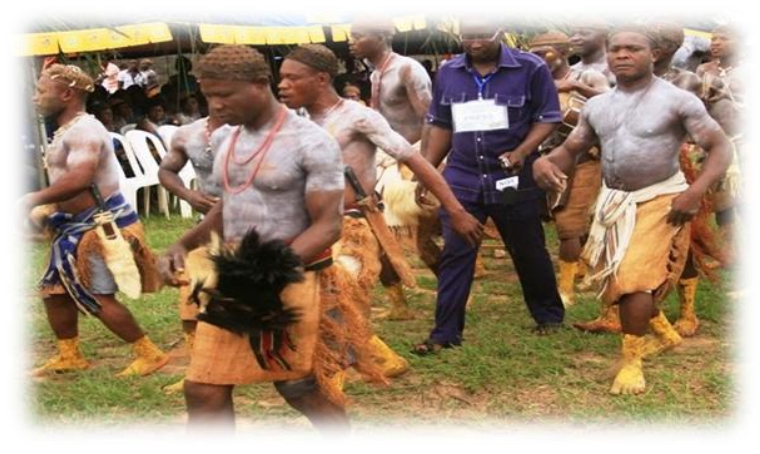

Leboku Festival

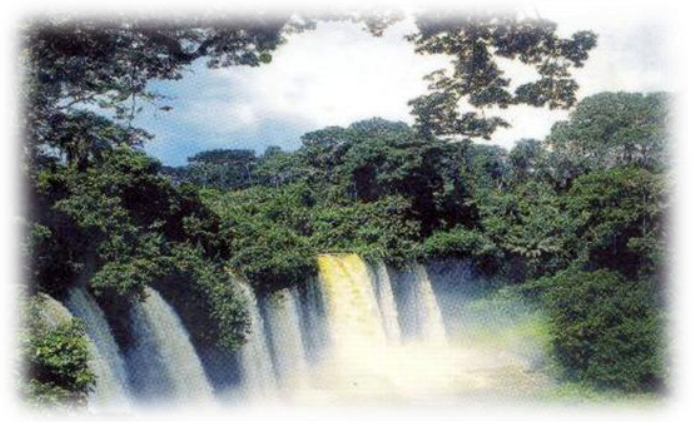

Cross River State National Park

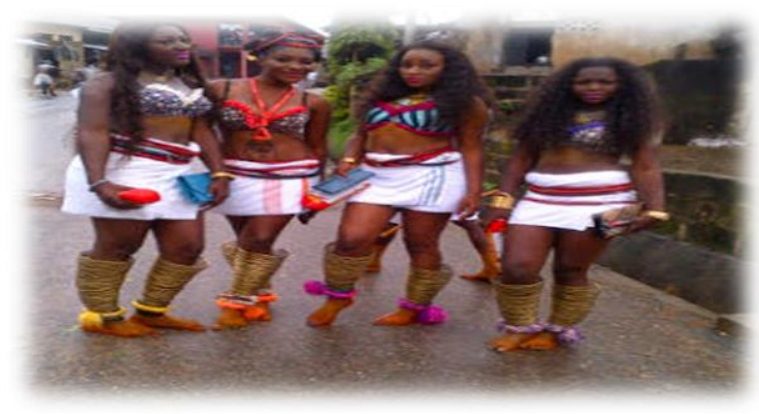

Leboku Festival

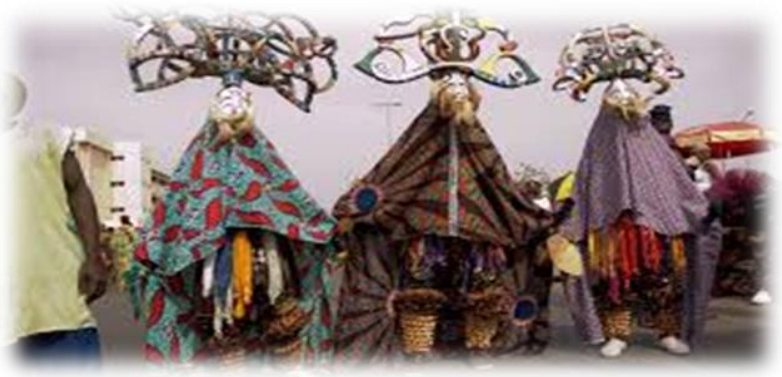

Leboku Festival

\section{REFERENCES}

Abbot, J. O., Thomas, D. L., Gardner, A. A., Neba, S. E., \& Khen, M. W. (2001). Understanding the links between conservation and development in the Bamenda Highlands, Cameroon. World Development, 29 (1), 1115-1136.

Aniah, E. J., Eja, E. I., \& Otu, J. E. (2009). Patronage of Ecotourism Potentials as a Strategy for Sustainable Tourism Development in Cross river State, Nigeria. Journal of Geography and Geology, 1 (2).

Awodele, O. A., \& Ayeni, D. A. (2011). Managing the Risks in Tourism Development Projects. Construction Management and Innovation , 1 (2), 105-129.

Ayeni, D. A., \& Ebohon, O. J. (2012). Exploring Sustainable Tourism in Nigeria for Development Growth. European Scientific Journal, September Issue, Vol. 8 (Iss. 208).

Backhaus, N. (2008). A landscape model for participation processes. . Retrieved November 15, 2015, from http://iasc2008.glos.ac.uk/conference\%20papers/papers/B/Backhaus_102702.

Besculides, A., Lee, M. E., \& McCormick. (2002). Residents Perceptions of the Cultural benefits of Tourism. Annals of Tourism Research , 29 (2), 303-319.

Bowler, J. M., English, D. B., \& Cordell, H. K. (1999). Outdoor recreation participation and consumption: Projections 2000-2050. In H. B. In Cordell (Ed.), Outdoor recreation in American life: Anational assessment of demand and supply trends (pp. 323-350). Champagne (IL): Segamore press Inc.

Chockalingam, M., \& Ganesh, A. A. (2010). Problems Encountered by Tourists. Peer Reviewed , 3 (3), 68-72.

Coldecott, J. O., Oates, J. F., \& Ruitenbeek, H. J. (1990). Cross River national park (Okwangwo Division): Plan for (1st ed.). (J. O. Coldecott, J. F. Oates, \& H. J. Ruitenbeek, Eds.) WWF-UK: Goldalming.

Cooper, C., Fletcher, J., Flyall, A., Gilberth, D., \& Wanhill, S. (2005). Tourism: Principle and Practice (3rd ed.). (C. Cooper, J. Fletcher, A. Flyall, D. Gilberth, \& Wanhill, Eds.) London: Pitman Publishing .

Eugene, E. E., Leif , M., \& Carolyn , A. A. (2010). Economic Value of Ecotourism to Local Communities in the Nigerian. Journal of Sustainable Development , 3 (1), 51-60.

Figueira, A. (2001). The role of planning in local and regional tourism development. Technologiae Gestao. Madrid: Reunion deEstudios. 
Foot, D. K. (1990). The age of outdoor recreation in Canada. Journal of Applied Recreation Research, , $15(3), 159-178$.

Godfrey, K., \& Clarke, J. (2000). Tourism Development Handbook: A Practical Approach to Planning and Marketing (1st ed.). (K. Godfrey, \& J. Clarke, Eds.) London: Thomson Learning EMEA.

Hall, M. C. (2007). Pro-poor Tourism: Who Benefits: Perspectives on Tourism and Poverty Reduction (1st ed.). (C. V. Publications, Ed.) Clevedone, UK: Channel View Publications.

Hill, J., \& Tim, G. (2009). Ecotourism and Environmental Sustainability: Principles and Practice (2nd ed.). (J. Hill, \& G. Tim, Eds.) Burlington: Ashgate Publishing Limited.

Isaac, J. C. (2000). The limited potential of ecotourism to contribute to wildlife conservation. The Ecologist , 21 (8), 61-69.

Kigoth, W. (2000). Gaining Ground. Business in Africa , 8 (1), 16-17.

Lindberg, E. K., \& Hawkins, D. E. (1993). Ecotourism: A Guide for Planners and Managers (1 ed.). (E. K. Lindberg, \& D. E. Hawkins, Eds.) North Bennington, Vermont.: The Ecotourism Society.

Maha , S. (2002). The selection of case studies: Strategies and their applications to IS. Res. Lett. Inf. Math. Sci. , 3, 191-198.

Manwa. (2012). Communities Understanding of Tourists and the Tourism Industry: The Lisotho Highlands Water Project. African Journal of Business Management , 6 (2), 6667-6674.

Mathieson A., W. G. (1982). Tourism: Economic, Physical and Social Impacts. (2nd ed.). (W. G. Mathieson A., Ed.) London: Longman.

Mihalia, T. (2000). Environment Management of a Tourist Destiantion a Factor of Tourism Competitiveness. Tourism Management, 21 (1), 65-78.

Nuva, R., \& Shamsudin, M. N. (2009). Willingness to Pay towards Conservation of Ecotourism Resources at Gunng Gede Pangrango National Park, West Java Indonesia. Journal of Sustainable Development , 2 (2), 173-186.

Ofem.O, O. (2012). Potentials of Developing the Cross River State National Park as an Ecotourism Resort, Nigeria. Academic Research International, 2 (3).

Oh, C. O. (2005). The Contribution of Tourism Development to Economic Growth in the Korean Economy. Tourism Management, 26 (1), 39-44.

Ottong, J., \& Bassey, A. O. (2009). Community development: principles and practice (1 ed.). (O. J.G, Ed.) Calabar: Index Books Publishers.

Pate, J., \& Loomis, J. (1997). The effect of distance on willingness to pay values: a case study of wetlands and salmon. Ecological Economics, 20 (1), 199-207.

Perujodi, N. (2011). An Assessment of Visitor Satisfaction with Nature-Based Tourism Attractions. International Journal of Tourism and Marketing , 4 (1), 185-210.

Raymond, Y. C. (2001). Estimating the Impacts of Economic Factors on Tourism; Evidence from Hong Kong. Tourism Economics , 7 (3), 277-293.

World Commission on Environment and Development (1987). Our common Future (1st ed.). (O. U. Press, Ed.) Oxford: Oxford University Press. www.un-documents.net/wced-ocf.htm (Accessed: 28/12/2015).

World Tourism Organization (2014) Tourism Highlights. A UNWTO publication, 2014 edition.

Zhenhna, L. (2003). Tourism Development: A Critique. Journal of Sustainable Tourism , 11 (6), 459-

475 . 